\title{
PENERAPAN METODE MODIFIED ANDREASEN PACKING MODEL PADA RANCANGAN CAMPURAN BETON NORMAL
}

\author{
Yulius Rief Alkhaly, Yuli Saturrahmi, Hernita \\ Jurusan Teknik Sipil, Fakultas Teknik \\ Universitas Malikussaleh \\ Cot Teungku Nie Kec.Muara Batu Kab.Aceh Utara PO BOX 141 Lhokseumawe \\ email:yr.alkhaly@unimal.ac.id
}

DOI: http://dx.doi.org/10.29103/tj.v7i2.131

\begin{abstract}
Abstrak
Perancangan campuran beton (mix design) merupakan upaya untuk menentukan besarnya jumlah semen, agregat halus, agregat kasar, dan air yang akan digunakan dalam $1 \mathrm{~m}^{3}$ adukan guna memperoleh kuat tekan rencana dan kemudahan kerja yang ditetapkan. Aspek keuntungan ekonomis campuran beton sangat ditentukan dari jumlah kandungan semen. Campuran beton dengan packing density yang baik akan menghasilkan jumlah kandungan semen yang lebih sedikit. Penelitian ini bertujuan untuk mengoptimalkan komposisi campuran beton dengan menggunakan metode Andreasen-Andersen packing model berbantuan perangkat lunak EMMA. Hasil penelitian menunjukkan bahwa penggunaan metode Modified Andreasen Packing Model menghasilkan campuran beton berkandungan semen lebih rendah, dan kuat tekan beton pada umur 28 hari lebih tinggi dibandingkan dengan metode SNI 032834-2000. Pada mutu beton rencana $15 \mathrm{MPa}-25 \mathrm{MPa}$, penggunaan semen lebih rendah $6 \%-9 \%$ dan kuat tekannya meningkat sebesar $6 \%-7 \%$. Selanjutnya pada mutu beton rencana $30 \mathrm{MPa}-40 \mathrm{MPa}$, penggunaan semen lebih rendah $14 \%-27 \%$ dan kuat tekannya meningkat sebesar 5\% - 13\%.
\end{abstract}

Kata kunci: perancangan campuran beton, packing density, kandungan semen, kuat tekan.

\section{Pendahuluan}

Beton normal dengan kekuatan tekan antara $15 \mathrm{MPa}$ - $40 \mathrm{MPa}$ merupakan jenis beton yang paling luas digunakan di Indonesia terutama untuk pembangunan perumahan rakyat, gedung-gedung pemerintah, dan konstruksi sipil lainnya. Beton normal dapat berupa beton yang menggunakan agregat alam dipecah (batu pecah) atau tanpa dipecah (kerikil). Jenis dan komposisi kandungan material pembetuk akan menentukan karakteristik beton normal saat keadaan plastis dan juga pada saat keadaan telah mengeras. Oleh karena itu, perancangan campuran beton, dengan metode tertentu dapat memprediksi karakteristik beton, merupakan suatu hal yang sangat penting (Fennis, Walraven and Nijland, 2008).

Perancangan campuran beton (mix design) merupakan upaya untuk menentukan besarnya jumlah semen, agregat halus, agregat kasar, dan air yang akan digunakan dalam $1 \mathrm{~m}^{3}$ adukan guna memperoleh kuat tekan rencana dan kemudahan kerja yang ditetapkan. Perancangan campuran beton normal haruslah memenuhi unsur persyaratan rancangan berupa aspek keuntungan ekonomis, dan hal ini sangat ditentukan oleh jumlah kandungan semen.

Salah satu cara mereduksi penggunaan semen per $1 \mathrm{~m}^{3}$ beton adalah dengan menggunakan bahan suplemen semen (supplementary cementitious materials, SCM). Dalam adukan beton akan terjadi reaksi kimiawi antara SCM dan Calsium Hiroksida $\left(\mathrm{Ca}(\mathrm{OH})_{2}\right)$ yang menghasilakan Calsium Silikat Hidrat (CHS) sekunder, sehingga SCM ini efektif mereduksi jumlah kandungan semen 5\% - 
30\% dan meningkatkan kinerja beton secara keseluruhan (Wong and Chan, 2013). Cara lain untuk mengurangi jumlah kandungan semen adalah dengan mereduksi rongga-rongga antar material granular agar didapat kerapatan volume yang optimum, metode ini dinamakan packing density (Hardjasaputra, Tirtawijaya and Tandaju, 2011). Packing density dari material granular pembentuk beton mempunyai pengaruh sangat besar terhadap karakteritik beton yang dihasilkan. Packing density yang baik memungkinkan reduksi terhadap kebutuhan air, faktor air semen $(w / c)$ menjadi lebih rendah, hal ini akan meningkatkan kekuatan tekan. Selain dari pada itu, packing density akan mereduksi bleeding dan segregasi, mereduksi permeabilitas, dan meningkatkan kontak pada area transisi (transition zone) agregat dengan pasta semen sehingga mereduksi porositas area transisi yang merupakan faktor dominan yang mempengaruhi kekuatan beton (Kwan and H.C.Henry, 2005).

Pada pengujian ini perancangan campuran beton dilakukan dengan motode yang tertuang dalam SNI 03-2834-2000 (Anonim, 2000). Kemudian hasil komposisi material terebut akan dioptimalkan dengan metode packing density: Modified Andreasen Packing Model berbantuan perangkat lunak EMMA (Elkem Materials Mixture Analyser) yang didapat secara gratis di www.elkem.com.

\section{Tinjauan Kepustakaan}

\subsection{Metoda perancangan campuran beton SNI 03-2834-2000}

Metode perancangan campuran beton dalam SNI 03-2834-2000 didasarkan pada metode Development of the Environment (DOE), Building Research Establisment, Inggris. Metode ini menggunakan beberapa asumsi (Alkhaly, 2016), yaitu:

a. Dapat digunakan untuk beberapa jenis semen: Ordinary Portland Cement (tipe I), Rapid-Hardening Portland Cement (tipe II), High Early Strength Cement (tipe III), dan Sulphate Resisting Portland Cement (tipe V);

b. Pengunaan jenis agregat yang berbeda (batu pecah atau kerikil) akan mempengaruhi jumlah penggunaan air;

c. Zona gradasi agregat halus diasumsikan berpengaruh pada tingkat kemampuan kerja dari campuran beton;

d. Penentuan jumlah volume curah agregat kasar per kubik beton didasarkan pada ukuran maksimum nominal dari agregat kasar dan gradasi agregat halus;

e. Tingkat kemudahan kerja yang diperlukan merupakan satu-satunya faktor yang diperhitungkan untuk menentukan kadar air dalam campuran beton, dinyatakan dengan uji slump atau uji VeBe;

f. Penentuan proporsi campuran tidak memperhitungkan pengaruh ukuran maksimum nominal dari agregat kasar;

g. Campuran beton hipotesis dengan rasio air semen (fas) 0,5 digunakan sebagai dasar acuan.

Langkah-langkah umum perancangan campuran beton berdasarkan SNI 032834-2000 diperlihatkan pada gambar berikut: 


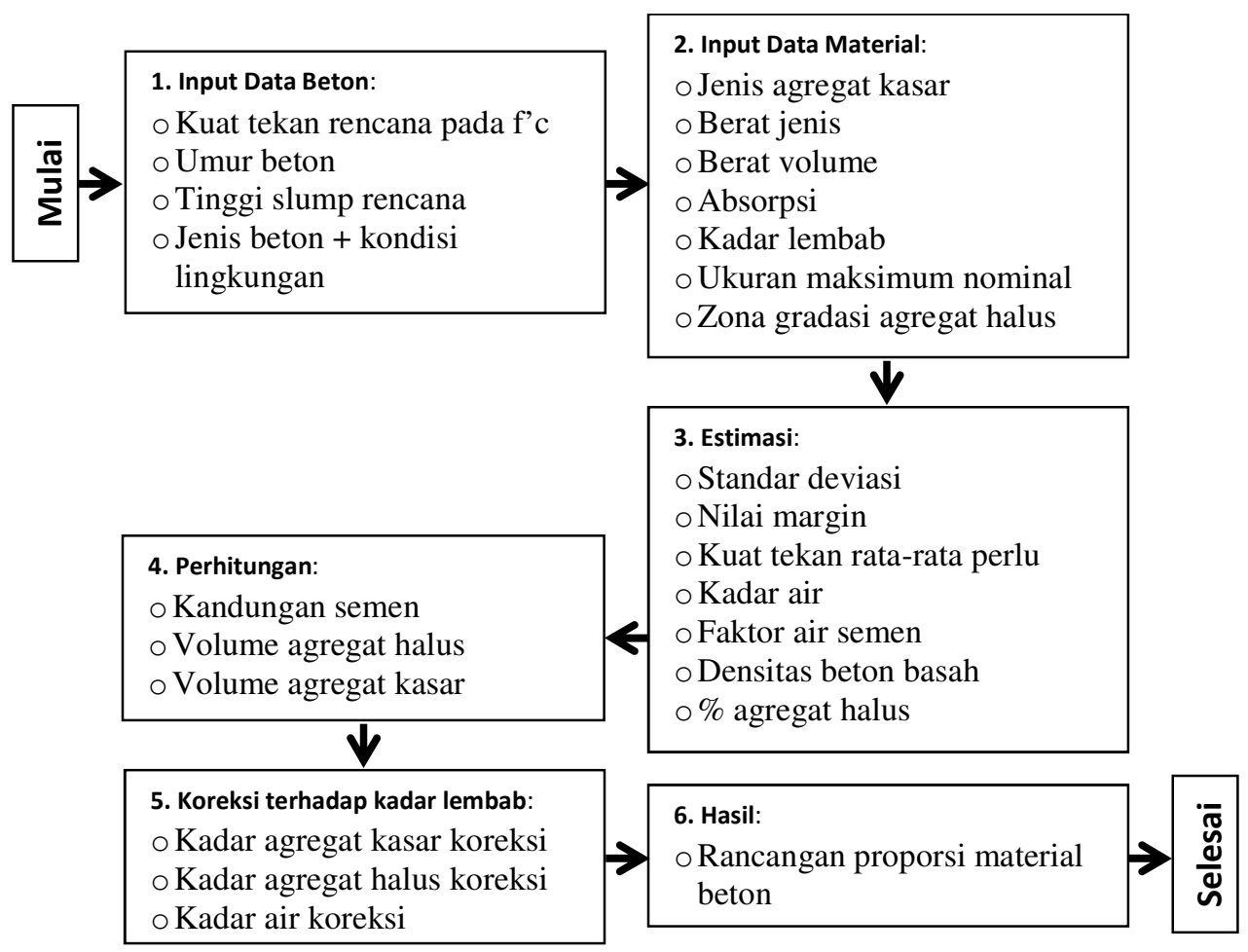

Gambar 1 Langkah-langkah rancangan campuran beton SNI 2000

Sumber: Alkhaly, (2016)

\subsection{Metode Modified Andreasen Packing Model}

Berdasarkan pendekatan gradasi menerus, packing density dari suatu sistem material granular sangat bergantung dari distribusi ukuran butir partikel. Oleh sebab itu, pemilihan fraksi tertentu dari material baku merupakan suatu cara untuk menghasilkan distribusi ukuran butir partikel yang ideal berupa gradasi menerus, sehingga menghasilkan packing density yang optimum (Müllera et al., 2014).

Agar didapatkan gradasi ukuran butir partikel berupa gradasi menerus yang ideal dengan packing density optimum, metode Modified Andreasen Packing Model (MAPM), yang merupakan suatu studi semi-empiris, memberikan formulasi sebagaimana dalam persamaan berikut (Gopinath et al., 2011):

$$
P(d)=\frac{d^{Q}-d_{\min }^{Q}}{d_{m a k}^{Q}-d_{\min }^{Q}}
$$

\section{Metode Penelitian}

\subsection{Material}

Semen yang digunakan berupa semen tipe I, merk Andalas, kualitas produk sesuai dengan SNI 15-2049-2004, dengan berat jenis 3,08. Selanjutnya, untuk perancangan campuran seluruh beton normal, agregat diambil dari sungai Kecamatan Sawang, Kabupaten Aceh Utara. Diameter maksimum agregat kasar (batu pecah) sebesar $19 \mathrm{~mm}$ dan agregat halus (pasir alam) dengan diameter maksimum yang digunakan sebesar $4,75 \mathrm{~mm}$. Sifat fisis keduanya diperlihatkan dalam Tabel 1, dan gradasi butiran agregat diberikan dalam Gambar 2. Air untuk pengadukan berasal dari Laboratorium Teknik Sipil, Universitas Malikussaleh. 
Tabel 1 Sifat fisis agregat

\begin{tabular}{|c|c|c|c|}
\hline & Uraian & $\begin{array}{c}\text { Agregat } \\
\text { halus }\end{array}$ & $\begin{array}{c}\text { Agregat } \\
\text { kasar }\end{array}$ \\
\hline Ukuran 1 & ssimum (mm) & 4,75 & 19,0 \\
\hline Berat & Kering jenuh-permukaan & 2,51 & 2,63 \\
\hline Jenis & Kering tungku/oven & 2,41 & 2,58 \\
\hline Absorps & & 4,48 & 1,68 \\
\hline Kadar le & $\mathrm{ab}(\%)$ & 1,29 & 1,30 \\
\hline
\end{tabular}

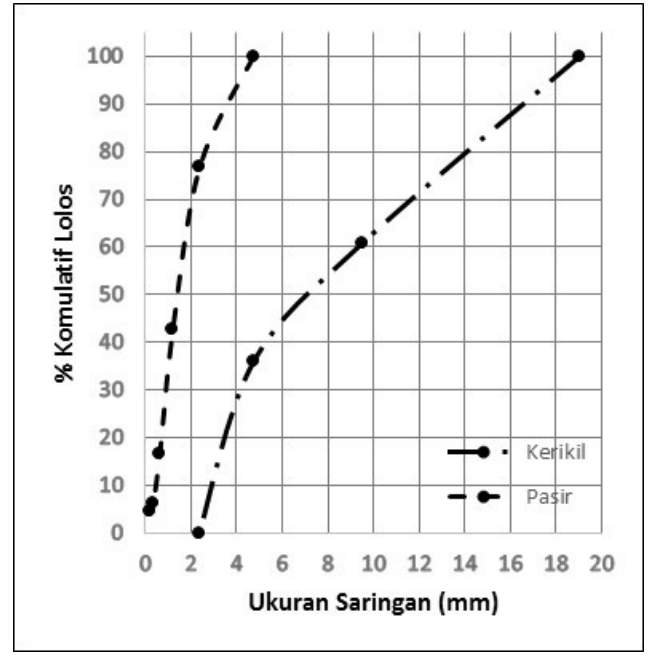

Gambar 2 Gradasi pasir alam dan batu pecah

\subsection{Prosedur pengujian}

Molen beton yang dipakai berupa jenis reversing drum (tipe laboratorium), urutan pengadukan material sebagai berikut:

- Agregat kasar, agregat halus, dan semen diaduk selama 2 menit,

- Seperdua jumlah air ditambahkan, diaduk selama 2 menit;

- Seperdua sisa air ditambahkan, diaduk selama 2 menit dan pengadukan dihentikan.

Selanjutnya, adukan beton dituangkan ke cetakan silinder ukuran $150 \mathrm{~mm}$ x $300 \mathrm{~mm}$ sebanyak 5 sampel untuk masing-masing varian benda uji. Setelah berumur satu hari, benda uji direndam dalam air sampai berumur 28 hari. Untuk uji tingkat kemudahan kerja campuran beton segar dilakukan dengan Slump test, menggunakan kerucut Abrams sesuai dengan SNI 1972:2008 (Anonim, 1990). Kekuatan tekan silinder beton diuji pada umur 28 hari mengikuti SNI SNI 031974-1990 (Elkem, 2016).

\subsection{Proporsi campuran}

Enam puluh benda uji yang terdiri dari 30 benda uji berdasarkan hasil perancangan dengan metode SNI 03-2834-2000 (selanjutnya disebut SNI), dan 30 benda uji hasil pengoptimalan dengan metode MAPM dibuat untuk pengujian slump dan kuat tekan. Proporsi material campuran untuk masing-masing kuat tekan rencana untuk kedua metode diperlihatkan dalam Tabel 2 dan Gambar 5. 
Tabel 2 Proporsi campuran beton

\begin{tabular}{|c|c|c|c|c|c|}
\hline \multirow{4}{*}{ Metode } & $\begin{array}{c}\text { Mutu beton } \\
\text { rencana (MPa) }\end{array}$ & Air (kg) & $\begin{array}{c}\text { Semen } \\
(\mathrm{kg})\end{array}$ & $\begin{array}{c}\text { Agregat } \\
\text { halus (AH) } \\
(\mathrm{kg})\end{array}$ & $\begin{array}{c}\text { Agregat } \\
\text { kasar (AK) } \\
(\mathrm{kg})\end{array}$ \\
\cline { 3 - 6 } & 15 & 280,78 & 380,00 & 803,42 & 838,80 \\
\hline \multirow{7}{*}{ SNI } & 20 & 278,20 & 427,00 & 763,72 & 834,08 \\
\cline { 2 - 6 } & 25 & 276,00 & 466,00 & 751,34 & 832,40 \\
\cline { 2 - 6 } & 30 & 232,90 & 528,00 & 728,60 & 804,76 \\
\cline { 2 - 6 } & 35 & 230,05 & 594,00 & 701,67 & 790,13 \\
\hline \multirow{4}{*}{ MAPM } & 40 & 222,88 & 641,00 & 667,84 & 778,11 \\
\cline { 2 - 6 } & 15 & 278,75 & 355,00 & 708,00 & 970,00 \\
\cline { 2 - 6 } & 20 & 276,20 & 398,90 & 655,00 & 989,00 \\
\cline { 2 - 6 } & 25 & 274,00 & 423,50 & 635,00 & 990,00 \\
\cline { 2 - 6 } & 30 & 228,67 & 451,00 & 632,00 & 1011,00 \\
\cline { 2 - 6 } & 35 & 222,88 & 465,00 & 620,00 & 1020,00 \\
\hline
\end{tabular}

\section{Hasil dan Pembahasan}

\subsection{Pengoptimalan rancangan campuran}

Enam jenis beton normal terdiri dari mutu $15 \mathrm{MPa}$ sampai mutu $40 \mathrm{MPa}$ dioptimalkan komposisi material pembentuknya menggunakan metode MAPM dengan bantuan perangkat lunak EMMA. Hasil akhir pengotimalan komposisi sebagaimana diperlihatkan dalam Tabel 2.

Packing density optimum dari campuran beton dapat diperoleh ketika nilai $\mathrm{q}$ (modulus gradasi) dari persamaan $1 \mathrm{di}$ atas diberi nilai lebih kecil dari 0,36 (Elkem, 2016). Pada pengujian ini, nilai q yang diinput ke perangkat lunak EMMA sebesar 0,34 dan tetap mempertahankan nilai faktor air semen. Hasil grafik luaran perangkat lunak EMMA untuk mutu beton $15 \mathrm{MPa}$ dan $40 \mathrm{MPa}$ diperlihatkan pada Gambar 3 dan 4 berikut ini:

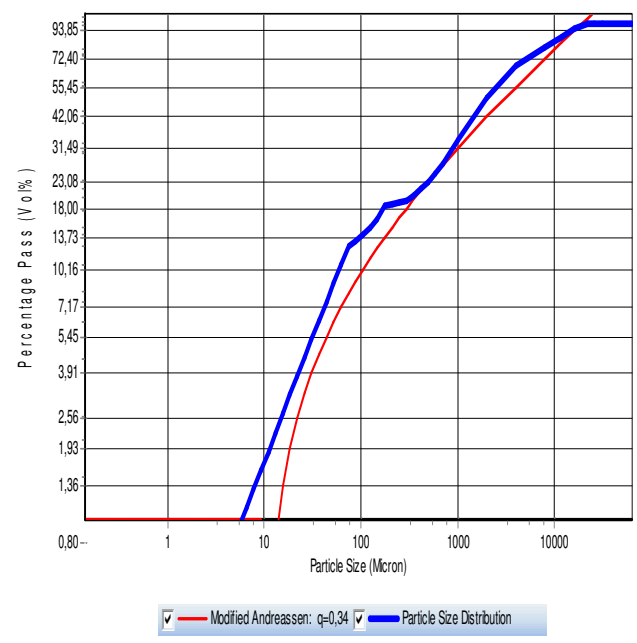

a. Gradasi SNI

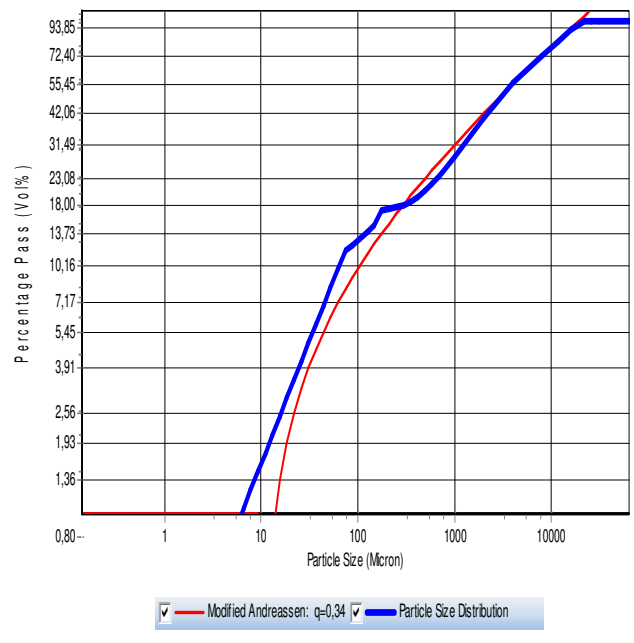

b. Gradasi MAPM

Gambar 3 Gradasi material granular metode SNI dan pengoptimalan gradasi dengan metode MAPM pada mutu beton $15 \mathrm{MPa}$ 


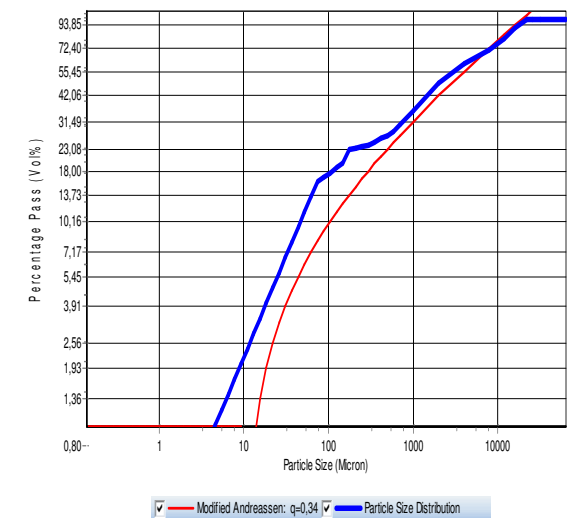

a. Gradasi SNI

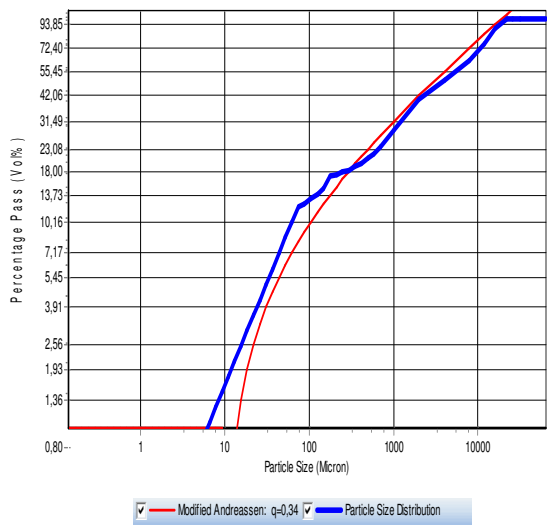

b. Gradasi MAPM

Gambar 4 Gradasi material granular metode SNI dan pengoptimalan gradasi dengan metode MAPM pada mutu beton $40 \mathrm{MPa}$

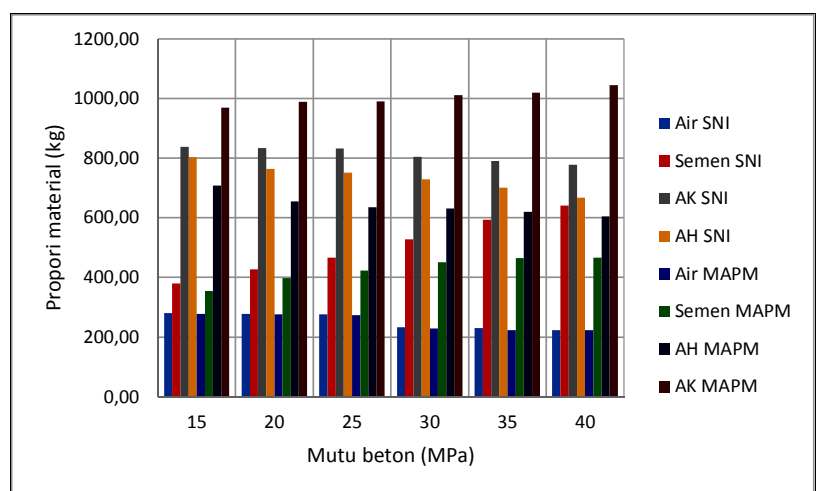

Gambar 5 Proporsi material campuran beton berdasarkan SNI dan MAPM

Berdasarkan Tabel 2 dan grafik-grafik di atas terlihat bahwa makin rapat gradasi material diselaraskan ke grafik ideal dari metode MAPM, jumlah kandungan semen dan pair semakin menurun, dan jumlah kandungan agregat kasar meningkat. Pada mutu beton rencana $15 \mathrm{MPa}-25 \mathrm{MPa}$, penggunaan semen lebih rendah $6 \%$ - 9\% dan pada mutu beton rencana $30 \mathrm{MPa}-40 \mathrm{MPa}$, penggunaan semen lebih rendah $14 \%-27 \%$.

\subsection{Kemudahan kerja dan kuat tekan}

Hasil pengujian kemudahan kerja menggunakan kerucut Abrams terhadap campuran hasil rancangan dengan metoda SNI dan pengotimalan dengan metode MAPM diperlihatkan dalam tabel berikut:

Tabel 3 Pengujian slump

\begin{tabular}{|c|c|c|c|}
\hline \multirow{2}{*}{ No } & Mutu beton & \multicolumn{2}{|c|}{ Nilai slump (cm) } \\
\cline { 3 - 4 } & rencana (MPa) & SNI & MAPM \\
\hline 1 & 15 & 9,0 & 8,0 \\
\hline 2 & 20 & 8,0 & 7,0 \\
\hline 3 & 25 & 7,0 & 6,5 \\
\hline 4 & 30 & 6,0 & 5,0 \\
\hline 5 & 35 & 6,5 & 5,0 \\
\hline 6 & 40 & 6,0 & 5,0 \\
\hline
\end{tabular}


Setelah pengoptimalan gradasi material granular, yang ditandai dengan bertambahnya kandungan agregat kasar, nilai kemudahan kerja (slump) campuran beton segar sedikit menurun, namun demikian masih dalam batas persyaratan 2,5 $\mathrm{cm}-12,5 \mathrm{~cm}$.

Mesin uji tekan hidrololik berkapasitas $2000 \mathrm{kN}$ yang telah dikalibrasi oleh KAN (Komite Akreditasi Nasional) digunakan untuk pengujian kuat tekan atas 60 (enam puluh) benda uji. Pengujian dilakukan setelah perendaman benda uji mencapai umur 28 hari. Kuat tekan rerata dari masing-masing 5 (lima) benda uji diperlihatkan dalam Tabel 4.

Tabel 4 Pengujian kuat tekan

\begin{tabular}{|c|c|c|c|c|}
\hline \multirow{2}{*}{ No } & \multirow{2}{*}{$\begin{array}{c}\text { Mutu beton } \\
\text { rencana (MPa) }\end{array}$} & \multicolumn{2}{|c|}{$\begin{array}{c}\text { Rerata kuat tekan 5 benda } \\
\text { uji (MPa) }\end{array}$} & $\begin{array}{c}\text { Varian kuat tekan } \\
\text { terhadap SNI } \\
(\%)\end{array}$ \\
\cline { 3 - 4 } & & SNI & MAPM & \\
\hline 1 & 15 & 18,80 & 19,98 & 6,28 \\
\hline 2 & 20 & 22,19 & 23,55 & 6,13 \\
\hline 3 & 25 & 26,05 & 28,06 & 7,72 \\
\hline 4 & 30 & 31,53 & 35,68 & 13,16 \\
\hline 5 & 35 & 36,91 & 39,91 & 8,13 \\
\hline 6 & 40 & 41,47 & 43,62 & 5,18 \\
\hline
\end{tabular}

Kuat tekan beton yang dibuat dengan berbagai mutu beton rencana terlihat meningkat setelah komposisi material dilakukan pengoptimalan dengan metode MAPM, sebagaimana ditampilkan dalam Tabel 4 di atas. Peningkatan kuat tekan tertinggi dicapai pada mutu beton rencana $30 \mathrm{MPa}(13,16 \%)$ dan peningkatan terkecil pada mutu beton rencana $40 \mathrm{MPa}(5,18 \%)$. Disini terlihat juga bahwa pada mutu beton rencana $40 \mathrm{MPa}$ didapat hasil kuat tekan melampaui $42 \mathrm{MPa}$ yang berarti mencapai batas kuat tekan beton mutu tinggi.

\section{Kesimpulan dan Saran}

\subsection{Kesimpulan}

Penerapan packing density dengan metode MAPM untuk pengoptimalan gradasi material granular metode SNI, memberikan hasil komposisi dengan berkurangnya kandungan semen dan pasir, bertambahnya kandungan batu pecah, kemudahan kerja memenuhi syarat, dan hasil kuat tekan meningkat. Penerapan metode MAPM memberikan tambahan nilai ekonomis dalam penggunaan material dibandingkan dengan metode SNI.

\subsection{Saran}

Penelitian ini membatasi nilai modulus gradasi (q) sebesar 0,34 sehingga diperlukan penelitian lanjutan dengan variasi nilai $\mathbf{q}$ yang lainnya agar dicapai gradasi material granular yang paling optimum. 


\section{Daftar Kepustakaan}

Alkhaly, Y. R. (2016) 'Perbandingan Rancangan Campuran Beton Berdasarkan SNI 03-2834-2000 Dan SNI 7656 $\square$ : 2012 Pada Mutu Beton 20 MPa', Teras Jurnal, 6(1), pp. 11-18.

Anonim (1990) Standar Nasional Indoneia (SNI) 03-1974-1990, Metode Pengujian Kuat Tekan Beton. Badan Standarisasi Nasional.

Anonim (2000) Standar Nasional Indoneia (SNI) 03-2834-2000, Tata cara pembuatan rencana campuran beton normal. Jakarta: Badan Standarisasi Nasional.

Elkem (2016) 'User Guide Elkem Materials Mixture Analyser - EMMA Contents', p. 35. Available at: www.elkem.com.

Fennis, S. A. A. M., Walraven, J. C. and Nijland, T. G. (2008) 'Measuring the packing density to lower the cement content in concrete', Tailor made concrete structures, pp. 419-424.

Gopinath, S. et al. (2011) 'Optimised Mix Design for Normal Strength and High Performance Concrete Using Particle Packing Method', Archives of Civil Engineering, 57(4).

Hardjasaputra, H., Tirtawijaya, J. and Tandaju, G. S. (2011) 'Ultra High Performance Concrete - Beton Generasi Baru berbasis teknologi nano', September, pp. 111-116.

Kwan, K. H. A. and H.C.Henry, W. (2005) 'Packing Density: A Key Concept for Mix Design of High Performance Concrete', in Proceedings of the materials science and technology in engineering conference, HKIE materials division. Hongkong, pp. 1-15.

Müllera, H. S. et al. (2014) 'Design and properties of sustainable concrete', Procedia Engineering. Elsevier B.V., 95(Scescm), pp. 290-304.

Wong, V. and Chan, K. W. (2013) 'Applying Theories of Particle Packing and Rheology to Concrete for Sustainable Development', Organization, Technology and Management in Construction an International Journal, $5(2)$. 